\title{
Spatial variability of trace elements with Moran's I Analysis for shallow groundwater quality in the Lower Katari Basin, Bolivian Altiplano
}

\author{
I. Quino ${ }^{1,2}$, O. Ramos ${ }^{1}$, M. Ormachea ${ }^{1}$, J. Quintanilla ${ }^{3}$ \& P. Bhattacharya ${ }^{2,3}$ \\ ${ }^{1}$ Laboratorio de Hidroquímica, Instituto de Investigaciones Químicas, Universidad Mayor de San Andrés, \\ La Paz, Bolivia \\ ${ }^{2}$ KTH-International Groundwater Arsenic Research Group, Department of Sustainable Development, \\ Environmental Science and Engineering, KTH Royal Institute of Technology, Stockholm, Sweden \\ ${ }^{3}$ International Center for Applied Climate Science, University of Southern Queensland, Toowoomba, \\ Queensland, Australia
}

\begin{abstract}
The southeastern part of the Titicaca Lake near the Cohana Bay in the Bolivian Altiplano, has environmental problems caused mainly by urban and industrial wastes upstream of the Katari Basin and by natural geological conditions. This environmental condition has generated an increase in the concentrations of some trace elements in the groundwater. The Moran's I statistic was used with LISA (Local Indicators of Spatial Association) method to know the spatial autocorrelation and the spatial variability of As, Sb, B, Al, Mn and F. Arsenic and antimony are the main pollutants due to natural geological conditions and boron due to the anthropogenic activities. Almost half of all the shallow groundwater samples exceeded the WHO and NB-512 guideline values mainly for antimony, boron and arsenic, whereby the spatial distribution of these trace elements in groundwater raises a significant concern about drinking water quality.
\end{abstract}

\section{INTRODUCTION}

Recent studies indicate that the Cohana Bay (Titicaca Lake) has environmental problems caused mainly by urban and industrial wastes upstream of the Lower Katari Basin (Fig. 1) and by natural geological conditions. The study area (91 communities) is located in the southeastern part of the Titicaca Lake, in the Bolivian Altiplano, with an area of $484 \mathrm{~km}^{2}$ (Fig. 1). Drinking water is extracted from excavated wells $(<10 \mathrm{~m}$ depth), these wells are also used for irrigation and animal consumption. The objective of this paper is to find the spatial variability using spatial autocorrelation of trace elements (As, Sb, B, Al, Mn and F), considering the hidrogeochemistry, the geographic information systems tools and the water quality of community consumption wells.

\section{METHODS/EXPERIMENTAL}

\subsection{Sampling and laboratory work}

Sampling was carried out during May 2015, 32 groundwater samples ( 32 communities) and 6 surface water samples were collected. The physicochemical parameters, $\mathrm{pH}$, temperature $(\mathrm{T})$, electrical conductivity (EC), redox potential (Eh) and total dissolved solid (TDS) were measured in the field with a multiparameter HANNA - HI 9828. Major anions were analyzed by Dionex ion chromatograph (ICS 1100) at the Environmental Chemistry Laboratory at Universidad Mayor

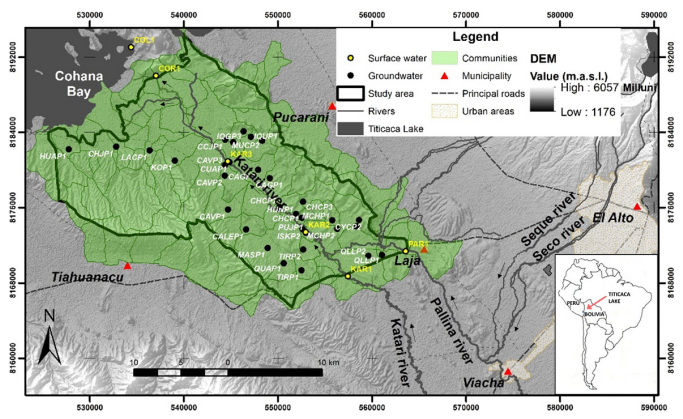

Figure 1. Study area and sampling points.

de San Andrés in La Paz Bolivia. Major cations and TEs were determined by inductively coupled plasmamass spectrometry at the Mineral Laboratories Canada of the Bureau Veritas Commodities Canada Ltd. in Vancouver Canada.

\subsection{Data analysis}

The Aquachem software (4.0.264 Waterloo Hydrogeologic Inc, 2003) was used to evaluate the analyses results for water samples and the type of water was determined. With the 32 sampling points, an interpolation was made for each TE using the deterministic method Inverse Distance Weighted (IDW). The interpolations were classified, to each of the $91 \mathrm{com}$ munities were assigned mean values according to the 


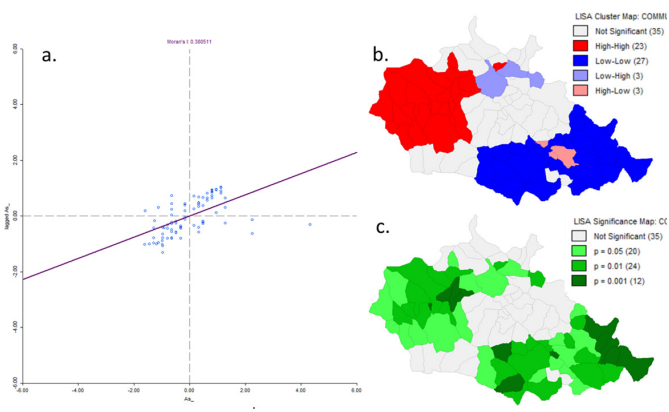

Figure 2. Global Moran's I statistiscal test (a), BiLISA Cluster Map (b) and BiLISA Significance Map (c) for As.

classified interpolation made. The percentage difference (PD) between the measured value and the value predicted by the interpolation was made for the 32 communities where the groundwater samples were taken. All these procedures were done in the ArcGIS 10.2.2 software.

The Moran's I statistic was used with LISA (Local Indicators of Spatial Association) method to know the spatial autocorrelation (SA) of each element. The global spatial dependence analysis (Global Moran's I statistiscal test), the local spatial dependence (BiLISA Cluster Map) and the significant spatial test (BiLISA Significance Map) were made in the GeoDa 1.12.01 software.

\section{RESULTS AND DISCUSSION}

\subsection{General hydrochemical characteristics}

The $\mathrm{pH}$ is slightly alkaline (7.8 mean), the Eh suggesting a moderately oxidizing environment $(189.3 \mathrm{mV}$ mean). High EC (279-7984 $\mu \mathrm{S} \mathrm{cm}^{-1}$ ) due to the lacustrine origin of sediments. $12.5 \%$ of the samples are of $\mathrm{Ca}-\mathrm{HCO}_{3}$ water type. $87.5 \%$ of the groundwater samples exceed the Bolivian regulation (NB-512) for $\mathrm{Sb}$ $\left(5 \mu \mathrm{g} \mathrm{L}^{-1}\right), 56.2 \%$ for $\mathrm{B}\left(300 \mu \mathrm{g} \mathrm{L}^{-1}\right)$ and $50 \%$ for $\mathrm{As}$ considering the WHO guideline values $\left(10 \mu \mathrm{g} \mathrm{L}^{-1}\right)$.

\subsection{Spatial variability of the trace elements}

The global spatial dependence analysis (Fig. 2a) gave values of Moran's I for As (0.38), Al (0.45), B (0.42), F (0.23), $\mathrm{Mn}(0.22)$ and $\mathrm{Sb}(0.19)$, these values indicate a positive autocorrelation and statistically significant for all cases, the p-value is 0.001 for the six cases. In the Cluster Map (Fig. 2b), spatial association statistic of Moran's I are presented, there are 23 High-high type communities, which are surrounded by communities with high concentration for $\mathrm{As}, 17$ for $\mathrm{Al}, 17$ for $\mathrm{Mn}, 16$ for $\mathrm{B}, 16$ for $\mathrm{F}$ and 13 for $\mathrm{Sb}$, there are also 27 communities of Low-low type, which are communities with low As concentrations that are surrounded by other communities of low concentration of As, for $\mathrm{B}$ are 27, 24 for $\mathrm{Mn}, 17$ for $\mathrm{F}, 16$ for $\mathrm{Al}$, and 15 for $\mathrm{Sb}$. In the significance map for As (Fig. 2c), the probabilities of the relationship of contiguity (adjacency) occuring in a random way are shown. 56 significant are highlighted for As, 52 for B, 46 for Mn, 39 for F, 33 for $\mathrm{Al}$ and 33 for $\mathrm{Sb}$. With a value that indicates an error probability of $0.001,0.01$ and 0.05 for all cases, in the rest the white color predominates indicating the absence of significance.

The spatial distribution of As shows a positive SA to the northwest (Cohana Bay) of the study area (Fig. 2b). The interaction between surface water and groundwater and the location of the wells around the volcanic formations and their dissolution could be the natural source of As. The B has a positive SA to the southeast of the study area, where the confluence of the Pallina and Katari rivers (alluvial, colluvio - fluvial deposits) is found. The aquifers are superficial and due to the agricultural activity present in the area could develop rapid processes of anthropogenic contamination (Molina et al., 2001). The Sb shows high spatial autocorrelation northeast of the study area where Devonian rocks exist as part of the Bolivian antimony belt of the Eastern Cordillera (Arce-Burgoa \& Goldfarb, 2009), this could explain the presence of $\mathrm{Sb}$ as the result mainly from weathering of carbonate rocks (Seal et al., 2017) of the Devonian.

\section{CONCLUSIONS}

The occurrences of $\mathrm{Al}, \mathrm{B}, \mathrm{As}, \mathrm{F}$ and $\mathrm{Sb}$ are not random and form significant groups in space. More than $50 \%$ of the samples exceed the NB-512 and WHO guidelines for $\mathrm{Sb}, \mathrm{B}$ and $\mathrm{As} . \mathrm{Sb}$ and $\mathrm{As}$ are the main pollutants due to natural geological conditions and boron due to the anthropogenic activities. The spatial distribution of dissolved $\mathrm{Sb}, \mathrm{B}$ and As concentrations in groundwater raises a significant concern about drinking water quality.

\section{ACKNOWLEDGEMENTS}

We are thankful to the Swedish International Development Cooperation Agency (Sida) for the SwedenBolivia cooperation program on research capacity development through Contribution: 75000553.

\section{REFERENCES}

Arce-Burgoa, O.R. \& Goldfarb, R.J. 2009. Metallogeny of Bolivia: Society of Economic Geologists Newsletter, 79(1): 8-15.

Molina, S.L., Sanchez, M.F., Pulido, B.A. \& Vallejos, I.A. 2001. Consideraciones sobre el boro en las aguas subterraneas del Campo de Dalias (Almeria). Geogaceta, 29: 79-82.

Seal, R.R., II, Schulz, K.J. DeYoung, J.H., Jr., with contributions from David M. Sutphin, Lawrence J. Drew, James F. Carlin, Jr., \& Byron R. Berger, 2017, Antimony, chap. C of Schulz, K.J., DeYoung, J.H., Jr., Seal, R.R., II, \& Bradley, D.C., eds., Critical mineral resources of the United States-Economic and environmental geology and prospects for future supply: U.S. Geological Survey Professional Paper 1802, p. C1-C17. 